\title{
Landslide Hazard Zoning in Na Heaw District, Loei Province, Northeastern Thailand
}

\author{
Namphon Khampilang*, Pradit Nulay \\ Department of Mineral Resources, Bangkok, Thailand \\ Email: *knamphon@gmail.com, geotech23kku@hotmail.com
}

How to cite this paper: Khampilang, N. and Nulay, P. (2019) Landslide Hazard Zoning in Na Heaw District, Loei Province, Northeastern Thailand. Open Journal of Geology, 9, 714-717.

https://doi.org/10.4236/ojg.2019.910083

Received: August 17, 2019

Accepted: September 22, 2019

Published: September 25, 2019

Copyright $\odot 2019$ by author(s) and Scientific Research Publishing Inc. This work is licensed under the Creative Commons Attribution International License (CC BY 4.0).

http://creativecommons.org/licenses/by/4.0/ (c) (i) Open Access

\begin{abstract}
Nahaew District in northeastern Thailand, where crops out the Cretaceous Khorat Group, is a priority area for landslide hazard assessment through landslide susceptibility and hazard zoning. Through an interpretation of Google Earth imagery, several landslides were mapped to create landslide inventory map. Parameter maps were constructed and compiled into a database with the landslide inventory. The bivariate (frequency ratio) statistical analysis was used to establish landslide susceptibility maps, which were classified into five susceptibility classes. Another approach was landslide hazard zonation. Urban and rural planning and engineering construction need especially hazard zonation map in medium and local scale. GIS and remote sensing techniques have many advantages in the preparation of the map including regional, medium and local scales. In this study, landslide zonation map was prepared using runout model by assigning engineering properties and Digital Elevation Model (DEM) as well as rainfall data. The result was landslide hazard zonation of the area and can be used for urban planning. The report and recommendation have contributed to local authority.
\end{abstract}

\section{Keywords}

Landslide Assessment, Slope Stability, Hazard Zoning

\section{Introduction}

Landslide, a significant natural hazard in the high mountain area, has drawn worldwide attention due to increasing awareness of its socioeconomic impacts, as well as, the increasing pressure of urbanization on the mountain environment [1]. Landslide study establishes a significant constraint to development and urban planning. Landslide susceptibility mapping can be the preliminary step in mitigating the damages [2]. Moreover, landslide susceptibility assessment is an 
important process for prediction and management of natural disasters. It is also a necessary step for integrated watershed management, hazard mitigation, and urban planning in government policies [3] [4]. A landslide susceptibility or hazard map depicts areas likely to have landslides in the future by correlating some of the principal factors that contribute to landslides with the past distribution of slope failures. Recently, DMR has been assigned to study about landslide hazard zonation in Na Haew District, Loei Province, NE Thailand.

\section{Study Area}

The Na Haew District is located between $17^{\circ} 16^{\prime} 43^{\prime \prime}$ and $17^{\circ} 35^{\prime} 43^{\prime \prime} \mathrm{N}$ latitudes and $100^{\circ} 49^{\prime} 50^{\prime \prime}$ and $101^{\circ} 107^{\prime} 36^{\prime \prime} \mathrm{E}$ longitudes. It covers a total area of approximately $625 \mathrm{~km}^{2}$. The study area is represented by the rocks of Phu Khat and Khao Ya Puk Formations.

\section{Data and Method}

In current study, a landslide inventory map was prepared using field surveys, local information, and satellite interpretation obtained from Google Earth software. The landslide scars found in Na Haew District were shown in Figure 1(a).

In this study, nine independent factors were chosen as potentially contributing to landslide susceptibility, slope, elevation, aspect, lithology, distance from drainage, distance from lineaments, NDVI, SPI and land-use. The availability of thematic data varies widely, depending on the type, scale, and method of data acquisition.

For landslide susceptibility mapping within $\mathrm{Na}$ Haew we choose statistical approach and frequency ratio methods. The landslide inventory map was compared with the various factor maps using a selected statistical method. By using statistical analysis, the factor and/or combination of factors that have resulted in slope instability in the past are determined. Quantitative predictions can then be made for areas where no landslides are currently present, but which have similar

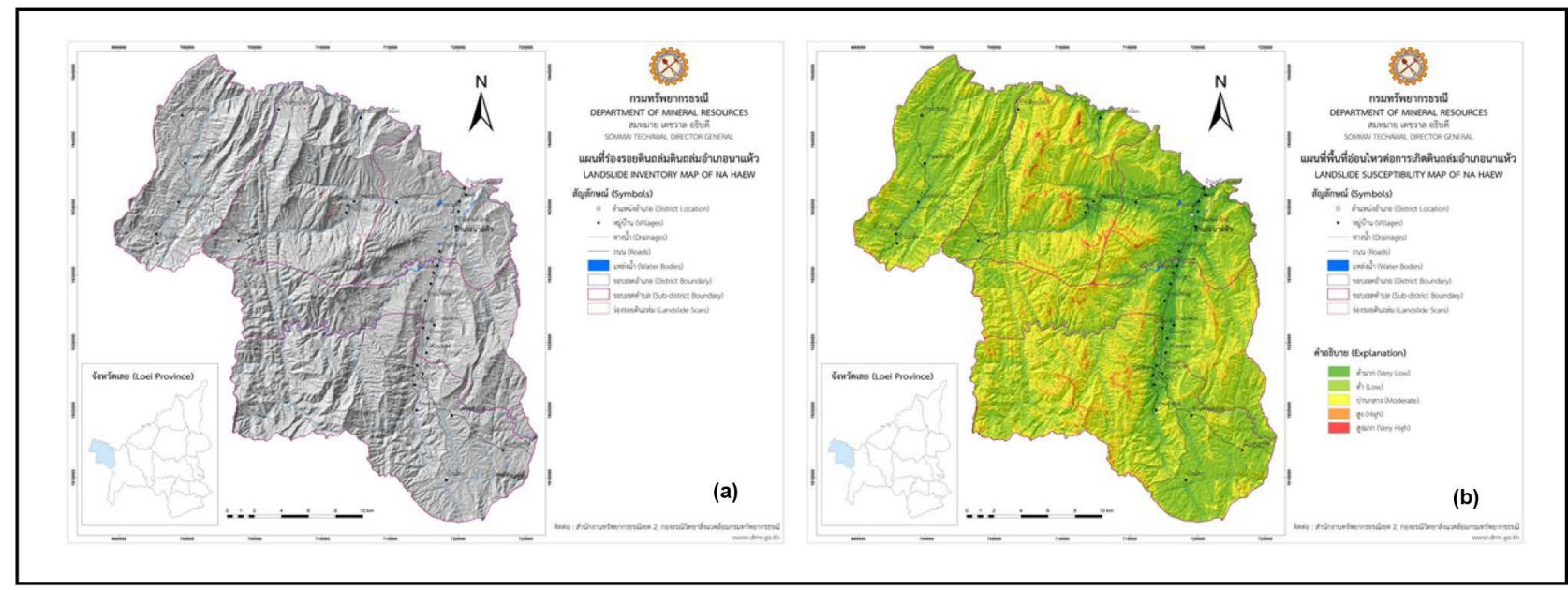

Figure 1. Landslide inventory map (a) and landslide susceptibility map (b) of Na Haew District. 
conditions to those where landslides exist. In frequency ratio ananysis the Frequency Ratio value $(F r)$ for each factor's range was calculated by dividing the landslide occurrence ratio by the area ratio. Then, the frequency ratios were summed to calculate the landslide susceptibility index $(L S I)$ as shown in Equation (1).

$$
L S I=\sum F r_{n}
$$

\section{Results}

Once a landslide susceptibility map is created, it is necessary to divide this map into different susceptibility classes. The simplest method is to assign the categories using expert opinion as done by [5]. The most common method for this purpose depends on the optimum bandwidth classification of the histograms of various parameters [6]. However, this is not straight forward as there are no statistical rules which can categorize continuous data automatically [7]. Recently, mathematical methods for data classification have become available in GIS software. In literature, there are many methods used [6] [7] [8]. These are based on manual or natural breaks, equal intervals, or statistical consideration, and can be described as follows. For the susceptibility classification for this study, the natural break method was used, and the susceptibility classes were divided into 5 classes (very low, low, moderate, high, very high) as shown in Figure 1(b).

\section{Acknoledgements}

This work is supported by DMR of Thailand and is a contribution to UNESCO/ IUGS/IGCP 679 project.

\section{Conflicts of Interest}

The authors declare no conflicts of interest regarding the publication of this paper.

\section{References}

[1] Aleotti, P. and Chowdhury, R. (1991) Landslide Hazard Assessment: Summary Review and New Perspectives. Bulletin of Engineering Geology and the Environment, 58, 21-43. https://doi.org/10.1007/s100640050066

[2] Regm,i A.D., Chandra, D.K, Yoshida, K., Pradhan, B., Pourghasemi, H.R., Kumamoto, T. and Akgun, A. (2014) Application of Frequency Ratio, Statistical Index, and Weights-of-Evidence Models and Their Comparison in Landslide Susceptibility Mapping in Central Nepal Himalaya. Arabian Journal of Geosciences, 7, 725-742. https://doi.org/10.1007/s12517-012-0807-z

[3] Carrara, A., Giovanni, C. and Frattini, P. (2003) Geomorphological and Historical Data in Assessing Landslide Hazard. Earth Surface Process and Landforms, 28, 1125-1142.

[4] Dahal, R.K., Hasegawa, S., Nonomura, S., Yamanaka, M., Masuda, T. and Nishino, K. (2008) GIS-Based Weights-of-Evidence Modelling of Rainfallinduced Landslides in Small Catchments for Landslide Susceptibility Mapping. Environmental Geology, 
54, 311-324. https://doi.org/10.1007/s00254-007-0818-3

[5] Dai, F.C. and Lee, C.F. (2001) Terrain-Based Mapping of Landslide Susceptibility Using a Geographical Information System: A Case Study. Canadian Geotechnical Journal, 38, 911-923. https://doi.org/10.1139/t01-021

[6] Akgün, A. and Bulut, F. (2007) GIS-Based Landslide Susceptibility for Arsin-Yomra (Trabzon, North Turkey) Region. Environmental Geology, 51, 1377-1387. https://doi.org/10.1007/s00254-006-0435-6

[7] Ayalew, L., Yamagishi, H. and Ugawa, N. (2004) Landslide Susceptibility Mapping Using GIS-Based Weighted Linear Combination, the Case in Tsugawa Area of Agano River, Niigata Prefecture, Japan. Landslides, 1, 73-81. https://doi.org/10.1007/s10346-003-0006-9

[8] Ayalew, L. and Yamagishi, H. (2005) The Application of GIS-Based Logistic Regression for Landslide Susceptibility Mapping in the Kakuda-Yahiko Mountains, Central Japan. Geomorphology, 65, 15-31.

https://doi.org/10.1016/j.geomorph.2004.06.010 